\title{
Hope versus Reality: 20 Years of Economic Transition at the Turkish States of the Central Asia
}

\author{
Prof. Dr. Mehmet Balc1lar (Eastern Mediterranean University, Cyprus)
}

\begin{abstract}
Twenty years passed now since the countries of the Central and East Europe (CEE) and the former Soviet Union (FSU) have begun the process of transformation from command to market economy and from one-party to a democratic rule. The transition process, at the beginning at least, started with very optimistic expectations in all countries. Transition is expected, as stated in the so-called 'Washington Consensus', create unprecedented growth and development. No one could envision failure and traps stuck the development and democracy. After 20 years, the transition economies clustered into different clusters and several development patterns have arisen along with countries that are trapped into almost no development. Among the clusters Turkic states of the Central Asia forms a unique cluster. This study makes a comprehensive attempt to analyze the development patters that have arisen along the way 20-year long. Experiences of 20 years are placed under the microscope to identify successes and failures with regards to both, theory and policy. We set a benchmark for success and successful transition and determine the key factors that have led to success or failure. In the light of the global crises, it easier to identify shortcomings of transition. Major conclusion arising from the study is that the original concept of the 'Washington Consensus' has failed to fulfill expectations of growth and development, the state of the art seems to be confusion.
\end{abstract}

JEL codes: P27, P36, O16

\section{Introduction}

The transition process to market economy, initiated in early 1990s, was process of political and economic reorganization, which affected the one fourth of the world population, undoubtedly became a rather unique historical experience. In the CEE the one-party political system that existed earlier has changed during a very short period. The collapse of the FSU has led to formation of 15 new independent states and with CEE countries 25 economies were classified as transition economies.

The study proceeds by considering the 'concept of transition' with the benefit of hindsight. Ouu particular conclusions are drawn from the experience of the Turkic states of the Central Asian Countries (CAC). Major conclusion arising from the study is that the original concept of the 'Washington Consensus' has failed to fulfill expectations of growth and development, the state of the art seems to be confusion (Rodrik, 2006).

The living standards in the CAC steadily declined in the last decade. Although the living standards in other former Soviet Union (FSU) and Central and East European (CEE) countries also declined, the decline in CAC countries was much radical. The literature attributed much of this decline to weak governance in the form of ineffective rule of law, inadequate protection of property rights, widespread corruption and ill-advised policymaking that serves special interests. The CAC are far from unique in facing a serious governance challenges. In many countries, practical experience has revealed that weak governance and slow economic development go hand in hand. It is also evinced by the experience in many countries that good governance encourages economic development.

The process through which governance affects economic development is not fully understood. The literature on governance has come to the conclusion that governance affects economic development through many interrelated and complicated channels which are hard to model in a simple way. In this paper, we argue that one of the channels governance affects economic outcomes works through its affect on the business. Poor governance shows up in excessive government intervention and discretion in economic activity, including excessive regulation of private sector entities and adaptation of preferential schemes, such as controls on the foreign exchange, trade, prices, credits, and tax exemptions. These offer extensive authority and opportunity for officials to use description in order to elicit bribes and kickbacks from those who benefit from the preferential treatment. Unfortunately, the preferential treatment leads to distorted markets and allow operation of inefficient firms producing low quality products resulting in huge welfare losses when overall consequences are considered for the whole economy.

The purpose of this study can be defined as follows. First, economic, political, and legal reforms varied considerably among the transition countries (particularly among the Central Asia (CA), and other FSU countries), which led to occurrence of so-called "development and transition patterns" in terms of economic and social achievements, such as the per capita GDP, investment and saving ratios, income distribution, life expectancy, child mortality, heath and social services, etc. What explains these development and transition patterns is the main focus of this study. The numerous studies concerning the economic and social gap developed among the CA and CEE countries (de Melo et al. 1997; Denizer 1997; Fischer et al. 1998) came to a conclusion 
that the economic reforms and initial conditions played a significant role. However, in recent years the view that governance - as defined in the next section-played a more significant role is gaining widespread acceptance (Abed 1998; Hellman et al. 2000, 2001). Until now, no empirical evidence has been obtained about the validity of this view. We do not know whether governance has played a considerable role on the economic development differentials of the CA, CEE and OFSU countries and whether it had any influence at all. Second, the literature mostly ignored the channels in which governance affects the economy. The most important effect of governance operates through the relationship between the government bureaucracy and private firms. The so called state capture should not be overlooked since it creates substantial economic costs in countries where it is a significant phenomenon. The paper obtains first time evidence that the economic development and governance in the transition economies are closely interrelated. The magnitude of this relationship is obtained using numerical data on governance. The econometric model estimates show that better governance leads to better economic development consequences. The quality of the evidence obtained in this paper is exceptional compared to the studies that examine the relationship among various factors and economic outcomes in transition countries.

The recent emphasis on the governance has lead to a reevaluation of the government's role and its relationship to the private sector. The old paradigms are now undergoing radical changes. When paradigms create more problems then they solve, they come under pressure and change becomes likely. The limitations of the old managerial approach to the operation of government are now coming to the light.

The rest of the paper is organized as follows. In the second section, we briefly explain the concept of governance, its various aspects that can be numerically measured, and its relationship to economic development. The econometric methodology used in the paper is explained and estimation results are presented in the third section. In the fourth section, we briefly discuss our findings.

\section{Governance and its Economic Significance}

In this study governance is defined as "a system of traditions and institutions determining how authority is exercised in a country." It includes (1) the processes of how governments are elected, reelected, and held accountable, (2) the capacity of governments to use the resources effectively, to formulate, implement, and enforce sound policies and regulations, and (3) the respect of citizens and government to institutions governing the interactions between them. The definition of governance in terms of above three components in relation to its functioning should not bee seen as final, but a practical definition for the purpose of this study. This type of clustering of governance is also conformable with the available data that can be used to measure the quality of governance. Following Kaufman et al. (1999a, 1999b) we will classify governance into six components corresponding to three cluster of governance defined above: (a) voice and accountability (VA), which includes freedom of speech and press independence, and political stability (PS) (b) government effectiveness (GE) in implementing good policies and providing quality public services, and regulatory quality (RQ), and (c) rule of law (RL), which includes protection of the property rights and independent judiciary, and control of corruption (CC).

Governance influences well-being and quality of life by direct and indirect channels which we do not fully understand. An improvement in one of the components of governance, for instance attainment of new civil liberties, will lead to improvement in quality of a life of the population of a country even if all other socio-economic variables do not change. Thus, governance is a direct input affecting the welfare of people living in a country. Additionally, there are also indirect effects. For instance, bad governance can negatively affect human capital accumulation and speed up exploitation of natural resources, which usually benefit certain elite groups. Furthermore, bad governments tend to adopt erroneous policies that reduce productivity, economic growth, and poverty alleviation. Therefore, an efficient and transparent government is vital for implementing and sustaining effective economic and institutional policies, human capital accumulation, and poverty alleviation, which affects these variables through direct and indirect complex channels.

The worldwide evidence shows that capable governments having good and transparent institutions are closely related to higher levels of per capita income, faster economic growth, higher welfare, and better social achievements. Only in the countries possessing effective, fair, and meritocratic state institutes, clear and well defined regulations, fair practicing of the law, political and legal systems not captured by the interest of elite groups, and citizens and press that have freedom of speech that helps holding governments more accountable, do we observe higher levels of income, investment, economic growth, and life expectancy.

The percentile rankings of transition countries in terms of six governance indicators are given in Figure 1. Overall, the transition countries rank worse than half of the 168 countries in the sample. In the transition economies, the democratic rights and freedom of the public is worse than half of the world countries, while in terms of control of corruption the transition countries rank much worse and only 30 percent of the world countries are below the transition countries. 

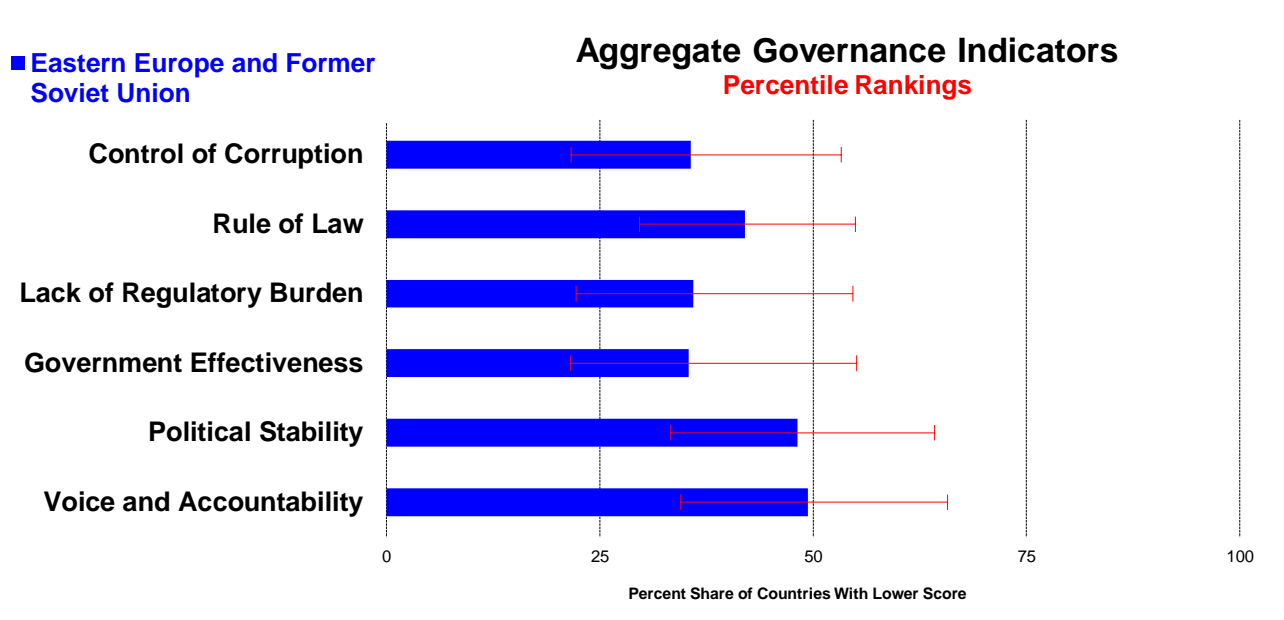

Figure 1. Aggregate Governance Indicators For Transition Countries

An indisputable fact is that despite identical institutional, geopolitical, cultural, and initial conditions in the CEE and OFSU countries, these countries progressed completely in different paths and a development gap arisen among these two groups since the beginning of the transition. The economic differences and development gaps are connected to governance before anything, i.e., the result of quality of intuitions and the manner in which how authority is exercised. This has been the major cause of transition recession lasting only three years in some countries, while lasting more than 10 years in others.

Before the transition began the CEE and OFSU countries were rather similar to other new market economies than they are today. Because of this similarity it was expected that these countries would have analogous structural problems. Although the difficulties and challenges facing these countries are coming closer since the beginning of transition, this expectation was not true then and it is not true today either. It would be a mistake to overlook the large gaps that exist between the CEE and FSU countries in terms the potential of economic development for the coming years and economic growth performance they had until today. Among the distinct factors that played a crucial role in the economic growth performance of the transition countries a rather important role is played by their achievement in institutionalization.

Among the FSU countries CAC faced the most difficult challenges and worse economic conditions. Although the disadvantaged initial conditions can explain the resulting economic collapse in the CAC to some extend, bad governance is a much more convincing explanation. In terms of governance quality the CAC are among the worst in the world. In order to illustrate the relative rankings of CAC, we show the measure of regulatory quality in CAC countries along with other 168 countries. The diamonds in the figure show the measure in 2001 while the dots show the ranking in 1998/99. The vertical lines are the standard errors of the measure of the regulatory quality. As we observe from Figure 2, in terms of regulatory quality CAC are among the worst in the world. It should come as no surprise that it is very hard for private sector to flourish and develop in such badly regulated economies.

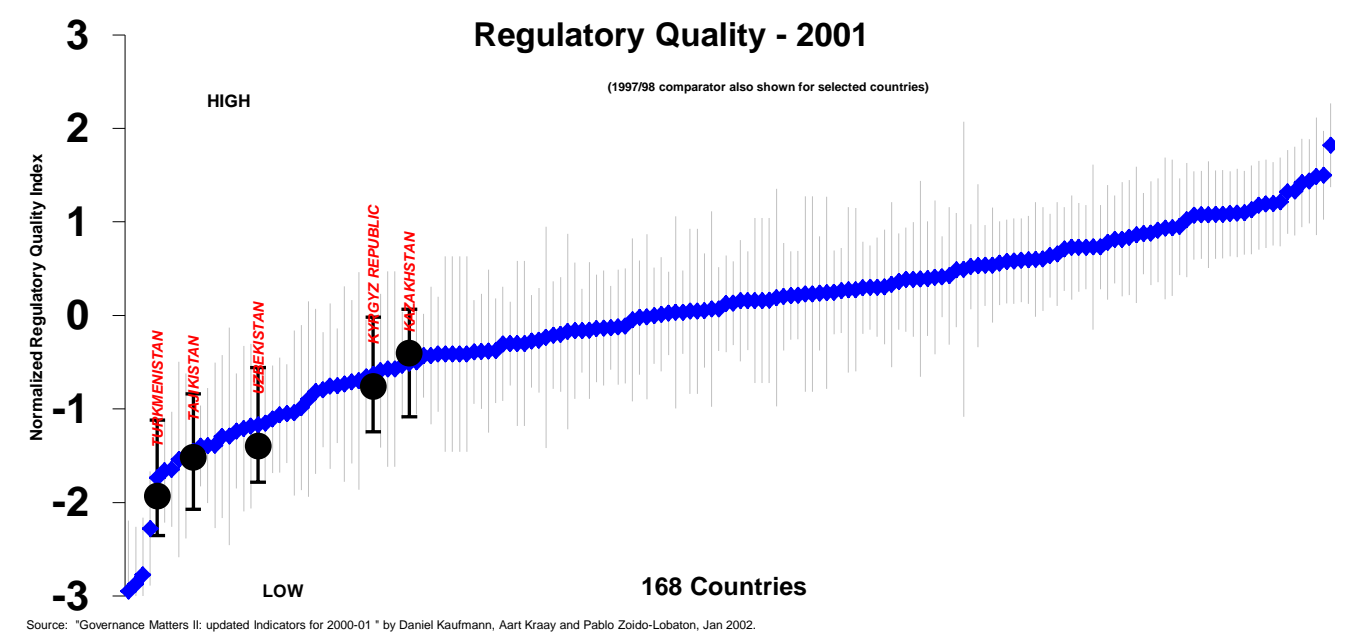

Figure 2. Regulatory Quality in Central Asia Countries 
This study asserts that the universal results claimed about the role of governance in the preceding paragraphs are the most important determinant of the development gaps that exists today among the transition countries. Furthermore, for these countries that are transforming from command to market economy governance has arisen as a crucial factor they lack and became a more determining their economic development. When the transition started the transition countries, particularly the FSU countries, lacked almost all necessary elements that makes up good governance. How much this has been a determining factor on the economic development can be seen from the impressive gaps grown among the countries of the CEE and OFSU.

\section{Econometric Specification and Estimation Results}

To investigate the interrelationship between development and governance in transition countries we use eight development measures and six attributes of governance explained above. The development indicators used in this study are purchasing power parity adjusted GDP per capita, investment rate as percentage of GDP, saving rate as percentage of GDP, life expectancy at birth, infant mortality rate, income distribution as measured by the Gini coefficient, percentage of population living in urban areas, tertiary school enrollment rate as percentage of population. The selection of these variables is based on practical consideration, their relationship with economic development, and data availability. We postulate that governance influences economic development through its complex effects on key variables, such as the investment and saving rates, quality of institutions, existence of sound development policies, etc., and we should observe a high correlation among the measures of governance and indicators of development.

Our econometric approach is similar to those used by Hall and Jones (1999) and Kaufman et al. (1999a, 1999b). To simplify the presentation, let $Y_{j}$ be a measure of economic development that we try to explain in the empirical specification. Thus, $Y_{j}$ denotes the value of the variable $Y$, such as the GDP per capita, investment rate, etc., in country $j$. For the per capita GDP, investment rate, and saving rate, the logarithm of $Y_{j}$ is used due to skewed distribution of these variables. Depending on the context it is used we will use $G_{j}$ to designate one of the following governance measures: voice and accountability (VA), political stability (PS), government efficiency (GE), regulatory quality (RQ), rule of law (RL), and control of corruption (CC). The basic econometric model specification used in the study is as follows:

(3) $G_{j}^{*}=G_{j}+W_{j}$

$$
\begin{array}{ll}
\text { (1) } & Y_{j}=\alpha+\beta G_{j}+U_{j}, j=1,2, \ldots, n \\
\text { (2) } & G_{j}=\delta+\theta Y_{j}+\gamma X_{j}+V_{j} \\
\text { (3) } & G_{j}^{*}=G_{j}+W_{j} \\
\text { (4) } & Y_{j}=\alpha+\beta G_{j}^{*}+\left(U_{j}-\beta W_{j}\right)
\end{array}
$$

where the error term $U_{j}$ captures the measurement errors in $Y_{j}$ and the effects of other variables, which influence economic development in the transition economies, but are not included in the specification in (1). In (1), $\alpha$ and $\beta$ are unknown parameters to be estimated. If the excluded variables are correlated with the governance measure $G_{j}$, this will lead to excluded variable bias in the model in (1), if this model is estimated by the ordinary least squares method (OLS). Governance may not possess a random distribution across countries. Developing good governance requires time and resources, which will lead to a system of simultenous equations. Governance is also related to variables such as the sociopolitical history, ethnic structure, and social infrastructure of a country. If we denote these other variables affecting the governance by the vector $X_{j}$, governance can be written as a function of development measures represented by $Y_{j}$ and other factors influencing governance, which are denoted by the $k \times 1$ vector $X_{j}$. These two considerations lead to the specification (2), where $V_{j}$ is a zero mean random error term representing the effect of unobservable variables on governance. In this specification, $\delta, \theta$, and the $k \times 1$ vector $\gamma$ are unknown parameters to be estimated. Other problem that should be addressed in the econometric specification is that the measurement of governance may be inexact. Empirical measures $G_{j}^{*}$ of governance will usually be noisy measures of true governance $G_{j}$. If the measurement error between $G_{j}^{*}$ and $G_{j}$ is denoted by $W_{j}$, then the relationship between $G_{j}^{*}$ and $G_{j}$ can be written as in (3), where $W_{j}$ is a zero mean disturbance term representing the measurement error. If we substitute equation (3) into equation (1), the empirical econometric specification, which formulates regressions of the measures of development on the measured governance indicators, can be written as in equation (4). In order to satisfy the identification condition for this model, we will assume that the determinants of governance contained in $X_{j}$ are not correlated with the composite error term $\left(U_{j}-\beta W_{j}\right)$ in (4). Under this assumption the variables in $X_{j}$ are valid instruments for observable measures of governance, $G_{j}{ }^{*}$. When such valid instruments are found the issues of excluded variable bias arising from the excluded variables in the empirical specification, the simultaneity bias arising from the feedback between $Y_{j}$ and $G_{j}$, and the measurement error bias can be overcome by using the two stage least squares (TSLS) method.

In these types of econometric specifications, the most difficult issue to resolve is to find valid instruments. We found that the instruments density of the spatial distribution of cities, ethnolinguistic fractionalization, and latitude are the most satisfactory in terms of the statistical criteria we set. 
The data used in the paper have been collected from various sources. The 25 transition countries included in the dataset are the CEE countries (Albania, Bulgaria, Croatia, Czech Republic, Hungary, Macedonia, Poland, Romania, Slovak Republic, and Slovenia), the OFSU countries (Armenia, Azerbaijan, Belarus, Georgia, Kazakhstan, Kyrgyzstan, Moldova, Russian Federation, Tajikistan, Turkmenistan, Ukraine, and Uzbekistan), and the Baltic countries (Estonia, Latvia, and Lithuania). Six measures of governance have been constructed by Kaufman et al (1999a, 1999b) for the periods 1997-1998, 2000-2001, and from 2002 to 2010 separately. These governance measures are constructed to have a zero mean and unit variance. Higher values of the governance indexes correspond to better outcomes. We use the average of these indexes for the 1997-2001 period. The variables related to economic development are obtained from the World Development Indicators 2010 database of the World Bank. The density of cities for each country is taken from Wyatt (2002). The index of ethnolinguistic fractionalization is equal to the percentage of population that speaks one or more some major foreign languages (German, French, English, Spanish, Portuguese, Russian, etc.). This index is constructed by Roeder (2001). In the paper the index of ethnolinguistic fractionalization designated as ELF85 by Roeder (2001) is used.

The estimation results for the econometric specification in (4) are given in Table 1. The results indicate a direct influence of better governance on economic development. Each panel in Table 1 gives result for one of the dependent variables we may relate to the left hand side variable in (4). For instance, in the first panel the dependent variable is the logarithm of per capita GDP and in the second the dependent variable is the logarithm of investment rate. Each line of each panel is related to the model obtained by taking one of the governance indexes, which are listed in the first column of Table 1, as the independent variable in the empirical specification in (4).

The second column of Table 1 reports the estimates of parameter $\beta$, which measures the influence of the governance index on the economic development variable. Based on the results of Hausman endogeneity tests, which are explained below, these parameter estimates are obtained by the TSLS, except for the saving rate, life expectancy, income distribution, and tertiary school enrolment, where endogeneity of the regressors are rejected and the parameters are estimated by the OLS. According to the $t$-statistics given in the fourth column of the table almost all parameters are significant at the five percent level, only exceptions are the regressions relating to the investment rate and tertiary school enrollment for which all estimates are not significant at the five percent level. The models relating to RQ and RL also have insignificant parameter estimates in the saving rate equation. The standard errors of regressions are given in the fifth column of Table 1 as a comparison criterion. We do not report $R^{2}$ for these regressions since it is not defined for the TSLS.

The signs of estimated parameters are in perfect harmony with theoretical expectations. Improvements in governance leads to higher per capita income, higher saving rates, higher investment rates, longer life expectancy, less infant mortality rate, more equal income distribution, higher percentage of the population living in urban areas, and more people getting higher education. In order to show the importance of estimators numerically, we note that the standard deviation of governance indexes is equal to one. Then, in the models for the per capita GDP, investment rate, and saving rate the estimated coefficients for governance indicators can be interpreted as the $100 \times\left(e^{\beta}-1\right)$ percent increase in the related variable due to one standard deviation improvement in the corresponding governance indicator. A one standard deviation improvement in governance will lead to 2.21-fold (in case of voice and accountability) to 3-fold (in case of rule of law) increase in per capita income, 1.10 -fold (in case of voice and accountability) to 1.16-fold (in case of rule of law) increase in saving rate, and 1.41 -fold (in case of voice and accountability) to 1.51 -fold (in case of rule of law) increase in investment rate. These results imply that small improvements in governance can lead to tremendous welfare gains and substantial increases in savings and investment. We observe that a one standard deviation in governance increases the life expectance by 0.65 years (in case of political stability) to 2.14 years (in case of rule of law). The infant mortality would decrease by 10 (in case of voice and accountability to 14 (in case of rule of law) infants per 1,000 live births. On the other hand, a one standard improvement in governance will lead to 4.3 percentage points (in case of voice and accountability) to 5.8 percentage points (in case of control of corruption) improvement in income distribution. If this had happened in Kyrgyzstan the income in Kyrgyzstan would have been distributed as equally as it does in Poland. The percentage of population living in urban areas would be 14.25 percentage points (in case of voice and accountability) to 18.07 percentage points (in case of rule of law) higher due to a one standard improvement in governance. Lastly, 2.29 percentage points (in case of regulatory quality) to 4.26 percentage points (in case of government efficiency) more of population would receive college or university education, if governance could have been improved by one standard deviation. 


\begin{tabular}{|c|c|c|c|c|c|c|}
\hline \begin{tabular}{|l|} 
Independent \\
Variable
\end{tabular} & $\beta$ & s.e. ${ }^{1}$ & $t$-stat. ${ }^{2}$ & $\begin{array}{c}\text { s.e. of } \\
\text { regress. }\end{array}$ & $\begin{array}{c}\text { Hausman } \\
\text { Test }^{4}\end{array}$ & $\begin{array}{c}\text { OIDR } \\
\text { Test }^{5}\end{array}$ \\
\hline \multicolumn{7}{|c|}{ Dependent variable: Logarithm of per capita income } \\
\hline VA & 0.793 & 0.169 & 4.703 & 0.232 & 0.006 & 0.624 \\
\hline $\mathrm{PS}$ & 0.975 & 0.167 & 5.839 & 0.158 & 0.004 & 0.863 \\
\hline GE & 0.984 & 0.158 & 6.242 & 0.141 & 0.022 & 0.974 \\
\hline RQ & 0.939 & 0.244 & 3.854 & 0.351 & 0.001 & 0.824 \\
\hline RL & 1.131 & 0.230 & 4.919 & 0.221 & 0.003 & 0.839 \\
\hline $\mathrm{CC}$ & 0.984 & 0.163 & 6.023 & 0.149 & 0.022 & 0.840 \\
\hline \multicolumn{7}{|c|}{ Dependent variable: Logarithm of investment rate, percent of GDP } \\
\hline VA & 0.099 & 0.089 & 1.113 & 0.065 & 0.056 & 0.719 \\
\hline $\mathrm{PS}$ & 0.145 & 0.099 & 1.459 & 0.056 & 0.367 & 0.853 \\
\hline GE & 0.142 & 0.105 & 1.342 & 0.063 & 0.051 & 0.849 \\
\hline RQ & 0.121 & 0.111 & 1.087 & 0.073 & 0.031 & 0.779 \\
\hline RL & 0.149 & 0.123 & 1.215 & 0.063 & 0.135 & 0.766 \\
\hline $\mathrm{CC}$ & 0.135 & 0.104 & 1.293 & 0.061 & 0.117 & 0.791 \\
\hline \multicolumn{7}{|c|}{ Dependent variable: Logarithm of saving rate, percent of GDP ${ }^{6}$} \\
\hline VA & 0.346 & 0.158 & 2.182 & 0.216 & 0.001 & 0.787 \\
\hline $\mathrm{PS}$ & 0.370 & 0.182 & 2.036 & 0.192 & 0.014 & 0.441 \\
\hline GE & 0.389 & 0.180 & 2.164 & 0.197 & 0.001 & 0.606 \\
\hline RQ & 0.376 & 0.213 & 1.770 & 0.277 & 0.001 & 0.671 \\
\hline RL & 0.414 & 0.208 & 1.985 & 0.214 & 0.001 & 0.545 \\
\hline $\mathrm{CC}$ & 0.375 & 0.172 & 2.184 & 0.181 & 0.006 & 0.492 \\
\hline \multicolumn{7}{|c|}{ Dependent variable: Life expectancy at birt ${ }^{6}$} \\
\hline VA & 1.648 & 0.527 & 3.130 & 4.192 & 0.859 & 0.024 \\
\hline PS & 0.644 & 0.689 & 0.933 & 5.760 & 0.284 & 0.048 \\
\hline $\mathrm{GE}$ & 1.885 & 0.695 & 2.714 & 4.528 & 0.544 & 0.017 \\
\hline RQ & 1.543 & 0.538 & 2.865 & 4.405 & 0.552 & 0.044 \\
\hline RL & 2.141 & 0.690 & 3.102 & 4.214 & 0.957 & 0.025 \\
\hline $\mathrm{CC}$ & 1.997 & 0.684 & 2.921 & 4.361 & 0.696 & 0.022 \\
\hline \multicolumn{7}{|c|}{ Dependent variable: Mortality rate, infant (per 1,000 live births) } \\
\hline VA & -10.207 & 2.071 & -4.930 & 34.951 & 0.103 & 0.692 \\
\hline $\mathrm{PS}$ & -11.302 & 3.148 & -3.591 & 56.222 & 0.045 & 0.346 \\
\hline GE & -11.734 & 2.296 & -5.110 & 29.821 & 0.393 & 0.233 \\
\hline RQ & -11.197 & 2.975 & -3.764 & 52.292 & 0.042 & 0.358 \\
\hline RL & -13.629 & 2.828 & -4.819 & 33.362 & 0.135 & 0.265 \\
\hline $\mathrm{CC}$ & -11.697 & 2.373 & -4.930 & 31.333 & 0.375 & 0.197 \\
\hline \multicolumn{7}{|c|}{ Dependent variable: Income distribution (Gini coefficient) ${ }^{6}$} \\
\hline VA & -4.284 & 1.664 & -2.575 & 41.846 & 0.974 & 0.868 \\
\hline $\mathrm{PS}$ & -4.673 & 1.871 & -2.498 & 42.402 & 0.964 & 0.721 \\
\hline $\mathrm{GE}$ & -5.261 & 2.131 & -2.469 & 42.615 & 0.841 & 0.766 \\
\hline RQ & -3.546 & 1.732 & -2.048 & 45.596 & 0.457 & 0.925 \\
\hline $\begin{array}{l}\mathrm{RL} \\
\mathrm{RL}\end{array}$ & -5.064 & 2.231 & -2.269 & 44.045 & 0.673 & 0.887 \\
\hline $\mathrm{CC}$ & -5.801 & 2.077 & -2.793 & 40.257 & 0.714 & 0.829 \\
\hline \multicolumn{7}{|c|}{ Dependent variable: Urban population, percent of total } \\
\hline VA & 14.249 & 4.258 & 3.346 & 147.813 & 0.013 & 0.262 \\
\hline PS & 15.056 & 5.186 & 2.904 & 152.594 & 0.047 & 0.090 \\
\hline $\mathrm{GE}$ & 15.914 & 4.909 & 3.242 & 136.302 & 0.044 & 0.107 \\
\hline RQ & 14.507 & 5.330 & 2.722 & 167.878 & 0.040 & 0.103 \\
\hline RL & 18.069 & 6.030 & 2.996 & 151.655 & 0.038 & 0.112 \\
\hline $\mathrm{CC}$ & 15.494 & 5.211 & 2.973 & 151.144 & 0.026 & 0.102 \\
\hline \multicolumn{7}{|c|}{ Dependent variable: tertiary school enrollment, percent of population ${ }^{6}$} \\
\hline VA & 3.674 & 3.780 & 0.972 & 116.498 & 0.155 & 0.031 \\
\hline PS & 3.869 & 4.370 & 0.885 & 108.373 & 0.544 & 0.020 \\
\hline $\mathrm{GE}$ & 4.259 & 4.419 & 0.964 & 110.452 & 0.324 & 0.024 \\
\hline RQ & 2.287 & 4.413 & 0.518 & 115.069 & 0.317 & 0.021 \\
\hline $\mathrm{RL}$ & 3.650 & 5.191 & 0.703 & 112.395 & 0.383 & 0.021 \\
\hline $\mathrm{CC}$ & 3.334 & 4.367 & 0.763 & 106.157 & 0.752 & 0.017 \\
\hline
\end{tabular}

Table 1. Estimation Results 


\section{Conclusion}

Economic evidence is accumulating which indicates that weak governance is detrimental to economic development and growth of the private sector. Weak governance lowers investment, reduces economic growth, distorts government spending, and aggravates income inequality. The cross-country data indicate a significant simple correlation between governance and socioeconomic outcomes. The empirical evidence suggests a large direct effect going from better governance to better development outcomes.

This study obtained the first empirical evidence on the close relationship between economic development and governance in transition economies. Using numerical indexes for six different elements of governance based on subjective evaluations of many organizations and researchers, strong evidence in favor of close relationship between governance and measures of development, which are defined as the purchasing power parity adjusted GDP per capita, investment rate as percentage of GDP, saving rate as percentage of GDP, life expectancy at birth, infant mortality rate, income distribution as measured by the Gini coefficient, percentage of population living in urban areas, and tertiary school enrollment rate as percentage of population, is obtained using econometric methods.

\section{References}

- Abed, G.T. (1998). “Governance Issues and Transition Economies.” Paper presented at the Conference on Challenges to Economies in Transition: Stabilization, Growth, and Governance.” Bishkek, May 27-28, 1998.

- de Melo, M., C. Denizer, A. Gelb, and S. Tenev. (1997). "Circumstance and Choice: The Role of Initial Conditions and Policies in Transition Economies." World Bank Policy Research Working Paper No. 1866, World Bank: Washington, D.C.

- Denizer, C. (1997). “Stabilization, Adjustment and Growth Prospevts in Transition Economies.” World Bank Policy Research Working Paper No. 1855, World Bank: Washington, D.C.

- $\quad$ Fischer, S., R. Sahay and C.A. Végh. (1998). "Stabilization and Growth in Transition Economies: The Early Experience", Journal of Economic Perspective, Vol: 10, No: 2, Spring, 45-66.

- Hall, Robert E., and Charles Jones. (1999). "Why Do Some Countries Produce So Much More Output per Worker than Others?" Quarterly Journal of Economics 114(1): 83-116.

- Hellman, J., G. Jones and D. Kaufmann. (2000). "Measuring Governance, Corruption, and State Capture: How Firms and Bureaucrats Shape the Business Environment in Transition Economies." World Bank Policy Research Working Paper No. 2312, World Bank: Washington, D.C.

(2001). "Seize the State, Seize the Day: State Capture, Corruption and Influence in Transition.” World Bank Policy Research Working Paper No. 2444, World Bank: Washington, D.C.

- Kaufmann, D., A. Kraay and P. Zoido-Lobatón. (1999a). “Aggregating Governance Indicators”. World Bank Policy Research Department Working Paper No. 2195, World Bank: Washington, D.C.

- _ _ (1999b). “Governance Matters”.World Bank Policy Research Working Paper No. 2196, World Bank: Washington, D.C.

- Rodrik, D. (2006). “Goodbye Washington Consensus, Hello Washington Confusion? A Review of the World Bank's Economic Growth in the 1990s: Learning from a Decade of Reform.” Journal of Economic Literature, Vol. XLIV (December 2006), pp. 973-987

- Roeder, P.G. (2001). "Ethnolinguistic Fractionalization (ELF) Indices, 1961 and 1985." February 16. <http://weber.ucsd.edu/ proeder/elf.htm>. (June 26, 2012).

- Wyatt, G. (2002). "Corruption, Productivity and Transition." Center for Economic Reform and Transformation Discussion Paper No. 2002/05, Heriot-Watt University: Edinburg. 